\title{
Corrigendum: Paradoxical hotspots for guanine oxidation by a chemical mediator of inflammation
}

Yelena Margolin, Jean-Francois Cloutier, Vladimir Shafirovich, Nicholas E Geacintov \& Peter C Dedon

Nature Chemical Biology 2, 365-366 (2006); published online 4 June 2006; corrected after print 23 January 2007

In the version of this article initially published, the $y$ axis of the graph in Figure 2 was incorrectly labeled. The axis should read "Ratio of Fpg- to piperidine-sensitive products," not "Ratio of piperidine- to Fpg-sensitive products." Accordingly, the text in the Figure 2 legend should read "ratio of Fpg- to piperidine-sensitive cleavage," not "ratio of piperidine- to Fpg-sensitive cleavage," and the text in the body of the paper (second page, second column, line 18) should read "Fpg- to piperidine-sensitive damage products," not "piperidine- to Fpg-sensitive damage products." The error has been corrected in the PDF version of the article. 